\title{
The Effect of an Intensive English Program on Malaysian Secondary School Students' Language Proficiency
}

\author{
Jayakaran Mukundan $^{1}$, Elaheh Hamed Mahvelati ${ }^{1} \&$ Vahid Nimehchisalem ${ }^{1}$ \\ ${ }^{1}$ Faculty of Educational Studies, Universiti Putra Malaysia, Malaysia \\ Correspondence: Jayakaran Mukundan, Department of Educational Studies, Faculty of Education, Universiti \\ Putra Malaysia, Serdang 43400, Selangor, Malaysia. Tel: 60-122-099-717. E-mail: \\ jayakaranmukundan@yahoo.com
}

Received: August 11, 2012 Accepted: August 23, 2012 Online Published: September 6, 2012

doi:10.5539/elt.v5n11p1 URL: http://dx.doi.org/10.5539/elt.v5n11p1

\begin{abstract}
Intensive English programs are courses in which students participate in a higher number of classes in a shorter period. The available literature on intensive English courses indicates inconsistent results necessitating further research in this area. This study investigated the effect of an intensive English program on a group of Malaysian Secondary School students $(\mathrm{n}=30)$ following a single group quasi-experimental design. Paired samples $\mathrm{t}$-test was used to analyze the students' scores before and after the treatment that lasted four weeks. The results indicated that the students scored significantly higher $(\mathrm{p}=.000<.05)$ at post-test. The study has useful implications for English as a Second Language (ESL) teachers, researchers, and curriculum developers. Further research is required before the findings of the study can be generalized.
\end{abstract}

Keywords: intensive English program, Malaysian secondary school students, school adoption

\section{Introduction}

The Intensive Program was arranged as part of the UPM-MRSM School Adoption Program, initiated by the first author from the Faculty of Educational Studies, Universiti Putra Malaysia (a research university in Malaysia). Its main objective was improving the general English proficiency of the low-scoring MRSM, Kuala Krai (Kelantan, Malaysia) students in English language courses. MRSM Maktab Rendah Sains Mara (in Malay), MARA Junior Science College (in translation) is a group of boarding schools scattered in 13 states of Malaysia. The MRSM schools were established in 1972 with the aim of providing better learning for bright Malaysian students.

The UPM-MRSM School Adoption Program commenced with a visit to the school in Kuala Krai, Kelantan by the first author and MARA officials in October 2011. Kelantan is a state in the north-east of Peninsular Malaysia, and Kuala Krai is a rural area in this state. The Intensive Program came to fruition as a result of the generosity of ELS Language Centers Malaysia (a strategic partner of UPM in the Tun Mahathir Scholarship Awards, developed by the Faculty of Educational Studies, UPM in 2000).

Thirty (30) of the lowest scoring students in English Language in Form 4 were listed for a one-month intensive program at ELS Language Centers, Subang Jaya. The 30 students stayed at the Chancellor College in UPM for the duration of the intensive course. They commuted to ELS, Subang Jaya by the MRSM Kuala Krai school bus. Two teachers from the school were assigned to supervise the group. Co-curricular activities were also planned, some of which involved visits, competitions and sports.

This paper presents the intensive English program that these students went through. Additionally, it aims to investigate the effectiveness of the program on the students' general English proficiency.

\subsection{Certified Intensive English Program (CIEP)}

The CIEP is the core program at ELS Language Centers, Malaysia and is offered at all 6 branches of the institute. The CIEP is a full-time proficiency course structured into 9 levels grouped as follows:

Beginning: $\quad$ Levels 101 to 103

Intermediate: Levels 104 to 106

Advanced: $\quad$ Levels 107 to 109 
The program is conducted full-time over 4 weeks per session (one session of 20 days). Each level of the program includes 28 lessons per week of classroom instruction and practice in all key language skills; speaking, listening, reading, writing, pronunciation, vocabulary and grammar. Classes are held Mondays through Thursdays from $8.30 \mathrm{am}$ to $3.30 \mathrm{pm}$, and on Fridays from $8.30 \mathrm{am}$ to $12.30 \mathrm{pm}$. Lessons are of 55 -minute duration and cover the following components:

Structure and Speaking Practice (SSP) 2 periods daily

Reading and Writing

2 periods daily

Conversation

1 period daily (Monday - Thursday)

LTC hour

1 period daily (Monday - Thursday)

The content of the program involves Reading and Writing, Structure and Speaking Practice (SSP), Conversation, and E-Learning Language Technology (LTC). Each of these components has been described briefly in this section:

\subsubsection{Reading and Writing}

Students learn to improve their reading comprehension and reading speed while practicing skills such as predicting content, skimming, scanning, drawing inferences and conclusions, guessing meanings of new vocabulary from context and summarizing information. Students then respond to the reading material through group discussions and writing in English.

\subsubsection{Structure and Speaking Practice (SSP)}

The SSP incorporates listening, speaking, vocabulary and grammar appropriate to specific levels to give students opportunities to practice language in real and meaningful situations. Students are trained to target accuracy through the application of both the form and the function in fun, activity-based situations.

\subsubsection{Conversation}

Students practice conversation skills using practical real world English and strategic skills that they are exposed to depending on their level of proficiency. The main purpose of this component is to build students' speaking fluency. Students get to express their views on different issues and on level appropriate themes which help broaden their vocabulary and functional use of the language.

\subsubsection{E-learning Language Technology (LTC)}

Students get to use the state of the art e-learning tools with interactive software for independent learning and to complement and supplement what they are taught in class.

A variety of materials were used for teaching each component. Conversation was taught using the session plans and the level specific online material that has been designed and developed for all CIEP Levels. ELS U.S. Proprietary Materials were used to teach Structure and Speaking Practice as well as Reading and Writing.

\subsection{Related Literature}

Intensive English programs, also called accelerated or compressed courses (Scott \& Conrad, 1992; Wodkowski, 2003), are the programs in which the students go through a relatively higher number of sessions in a shorter period than normal. The effectiveness of intensive courses has been a matter of controversy in recent years. While some researchers, such as Burton and Nesbile (2002), Bédard and Thomas (2010), Grant (2001) as well as Messina (1996), have reported positive results associated with intensive instructional formats, some other (e.g., Bateson, 1990; Nasiri \& Shokrpour, 2012), have raised doubts about the efficacy of these programs and highlighted their disadvantages in their studies.

Proponents of intensive teaching formats claim that intensive courses can facilitate learning in a variety of academic disciplines, such as algebra and accounting (Caskey, 1994), educational psychology (Brackenbury, 1987), mathematics (Spurling, 2001), literature (Scott, 1994), foreign language (Buzash, 1994; Jacques-Bilodea, 2010, Nagano, 1995), and business (Van Scyoc and Gleason, 1993), in a shorter period.

According to Nagano (1995), a one-week intensive English course could affect not only the learners' achievement but also their attitude toward learning English positively. Research also shows that intensive English programs for young learners lead to better results than regular English programs offered over a school year (Spade \& Lightbown, 1994). Intensive English programs have been found to contribute to learners' basic interpersonal communications skill and cognitive academic language proficiency (Hong- Nam \& Leavell, 2006) as well as their time management skills (Grant, 2001). Additionally, studies show that intensive programs can 
increase learners' motivation, commitment and engagement, and that learners believe intensive programs are more stimulating, exciting, efficient, challenging and enjoyable than regular courses (Burton \& Nesible, 2002; Daniel, 2000; Jacques-Bilodea, 2010; Scott \& Conrad, 1991). Intensive programs can also lead to learners' better attendance and concentration (Daniel, 2000; Grant, 2001). Austin and Gustafson (2006) explored the possible differences between intensive and traditional semester-length courses by using a database of over 45,000 observations from different semesters, and found out that intensive courses were more beneficial for the learners. Similarly, the findings of Raymond's study (1995) proved that intensive English programs could have a significant positive effect on language knowledge development of the learners (Cited in Jacques-Bilodea, 2010). More precisely, Raymond (1995) compared the oral and written competencies of the students in an intensive English course with the students in a regular course and showed that the students from the intensive program outperformed the regular students in both oral and written comprehension abilities. In addition, the students who had participated in intensive courses during their primary school years were interviewed at the end of each school year during high school since Raymond sought to investigate the long-term effect of the intensive English programs. As Raymond put it, the success of $78 \%$ of the students in carrying on an English conversation with the interviewer indicated that the intensive programs had durable effects. In summary, the advocates of intensive courses claim that these programs can have a crucial role in developing the learners' basic academic knowledge, fostering their communicative skills, improving student-teacher rapport, and facilitating active learning and creative instructional techniques (Gaubatz, 2003).

Other researchers have reported different results, however. Nasiri and Shokrpour (2012) compared the effect of an intensive and a non-intensive English course on 170 freshmen students' performance at the international branch of Shiraz University of Medical Sciences, in Iran. The intensive course comprised a prerequisite and a compulsory reading course held 10 hours a week. The non-intensive course was held 4 hours a week and overall lasted for 68 hours but twice as much for the intensive course. The same textbooks were taught in both courses. According to the results, the students in the non-intensive group indicated significantly better performance than those in the intensive group. Consistent with Nasiri and Shokrpour's (2012) findings on the ineffectiveness of the intensive courses, Gallow and Odu (2009) also report that intensive programs are not an optimal way for learning English even though most students prefer them since they reduce the length of the period they are obliged to be in the classroom. It has been argued that psychologically learning improves when students go through the new subjects not intensively but scheduled over longer periods in fewer but longer class hours. Scott and Conrad (1991) contend that intensive courses may result in learner's fatigue and their failure to digest the new subjects due to the rapid assignments that do not allow extensive coverage of the new concept. Research shows that learners who followed regular programs achieved significantly higher results than those that participated in intensive courses (Bateson, 1990). It is argued that compressed courses push learners to proceed to new concepts before they have completely reviewed and mastered the older lessons (Henbery, 1997). Reportedly, intensive courses can overload the learners, increasing their anxiety (Daniel, 2000; Scott \& Conrad, 1991). As this review of the related literature demonstrates, studies conducted on the effectiveness of intensive programs report inconsistent results. Furthermore, in spite of these intense debates over the issue, there are a scant number of empirical studies which focus specifically on the outcomes of intensive English programs. This necessitates further research in the area.

\subsection{Objective and Research Question}

The study aimed at investigating the effect of an Intensive English Program on a group of low scoring students' general English language proficiency. In order to meet this objective the following research question was addressed:

Does the Intensive English Program have any significant effects on the low scoring school students' general English language proficiency?

Within the scope of the present study, the effect of the program on the learners' general English language proficiency was measured by a comparison of the difference between their pre- and post-test scores upon their admission to the program and their completion of the program. The pre- and post-tests involved the standard ELS placement test that focuses on the four language skills (listening, speaking, reading, and writing) as well as the sub-skills of grammar, spelling and pronunciation.

\section{Method}

Quantitative method was followed to address the research question. More specifically, a single group quasi-experimental design was employed in this study. This section presents the participants, procedure, tests and instrumentation as well as the data analysis method of the study. 


\subsection{Participants}

The participants (22 males and 8 females, aged 16) were Form 4 school students from MRSM Kuala Krai, Kelantan, Malaysia. Since the objective of the study was to find out whether the Intensive English Program would have a significant effect on the weak students' general English language proficiency, the lowest scoring students in English Language in Form 4 were chosen for this study.

\subsection{Procedure}

Thirty (30) of the lowest scoring students in English Language in Form 4 were listed for a one-month intensive program at ELS Language Centers, Subang Jaya in December 2011. The 30 students stayed at a dormitory in UPM for the duration of the intensive course. They commuted to ELS, Subang Jaya by bus. Before their admission, they sat the ELS Placement Test (pre-test). Based on their performance, they were distributed across 5 levels in the Certified Intensive English Program (CIEP), levels 101 to 105 with most being placed in high elementary, 103 (Table 1).

Table 1. Distribution of the students across the five levels

\begin{tabular}{lll}
\hline Level & Frequency & Percentage \\
\hline 1 & 1 & 3.3 \\
2 & 8 & 26.7 \\
3 & 17 & 56.7 \\
4 & 3 & 10 \\
5 & 1 & 3.3 \\
\hline
\end{tabular}

Table 1 shows the distribution of the students in the five levels. Following the placement test, all the students went through the CIEP at their respective levels, as described previously. The dominant methodology used in the program included the communicative language learning, a learner centered approach which encourages active student participation and interactive, activity-based learning.

Additionally, co-curricular activities were planned, some of which involved visits, competitions and sports. The students toured not only places of interest (like Historical Melaka, $120 \mathrm{~km}$ to the south of Kuala Lumpur) but universities like Universiti Tenaga Nasional (UNITEN) where they were exposed to motivational talks. They were also involved in sports activities at UPM and UNITEN. Additional workshops were conducted by post-graduate students during weekends in UPM. Another special activity that the students experienced was a combination of intensive and extensive reading task, called the Readerthon. Each student was given ten different volumes of the Just English magazine. The students would read the magazines for gaining fluency (extensive reading), but in a rather short period of two days, over the weekend. They were, then, given a worksheet with 20 short-answer questions about the texts they had read in the magazines (intensive reading). Following the treatment, the students were given a post-test, which was almost the same as the pre-test.

\subsection{Tests and Instrumentation}

The pre- and post-tests were the standard placement test of ELS. This includes an oral interview, a writing task and a multiple-choice test. The instrument that was used to rate the written samples was the ESL Composition Profile (Jacobs Jacobs, Zingraf, Wormuth, Hartfiel \& Hughey, 1981). As a generic analytic scale, the ESL Composition Profile focuses on five sub-constructs of writing; that is, content, language use, organization, vocabulary and mechanics. The total score can range from 34 (the lowest possible score) to 100 (the highest possible score).

\subsection{Data Analysis Method}

SPSS (Version 18) was used for analyzing the data. Paired sample t-test was used to test the significance of the difference between the students' pre- and post-test scores.

\section{Results and Discussion}

In order to answer the research question dealing with the effect of the intensive English program on the subjects' general English language proficiency, the pre-test scores of the participants in the experimental group were compared with their post-test scores (Table 2). 
Table 2. Descriptive statistics for pre and post-test scores

\begin{tabular}{llll}
\hline & $\mathrm{N}$ & Mean & SD \\
\hline Pre-test & 30 & 49.5 & 4.04 \\
\hline Post-test & 30 & 79.17 & 3.37 \\
\hline
\end{tabular}

Table 2 indicates the descriptive statistics for the pre and post-test scores. As the table demonstrates, the students scored considerably higher at post-test $(M=79.17, S D=3.37)$ as compared with their scores at pre-test $(M=$ $49.5, S D=4.04)$. There was a mean difference of 29.67 between the students' scores in the two tests. Paired samples t-test was also used to test the statistical significance of this difference (Table 3).

Table 3. Paired samples t-test results

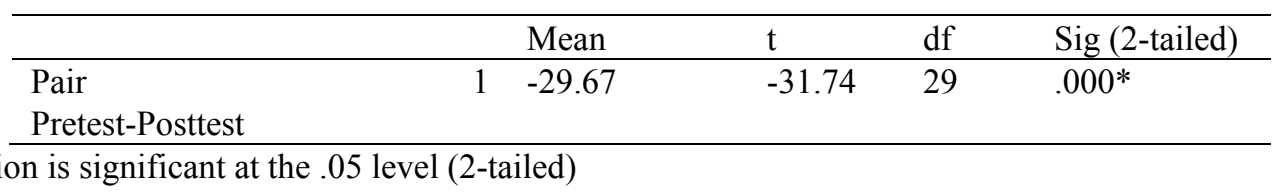

* Correlation is significant at the .05 level (2-tailed)

According to the table, the difference between the pre-test and post-test scores was statistically significant $[\mathrm{t}(29)=31.74, \mathrm{p}=.000<.05]$. That is, the effect of the one-month intensive program at ELS Language Center on the learners' language knowledge development proved to be significantly positive.

The results of the present study revealed that in the case of the low scoring learners, intensive English courses could be of great help in enhancing language proficiency. The marked difference between the means of the pre-test and post-test (Mean difference $=29.67$ ) lends support to the findings of the previous studies which proved the efficiency of intensive teaching and learning formats (Bédard \& Thomas, 2010; Burton \& Nesbile, 2002; Grant, 2001; Spurling, 2001). Moreover, the findings of this study are consistent with Raymond (1995, cited in Jacques-Bilodea, 2010) and Lightbown and Spada's (1994) studies that indicated intensive English programs have an effective role in improving learners' oral and written language competencies. These studies suggest that although language learners do extend their general knowledge of English through regular courses, their progress can be considerably hastened in intensive English courses.

Similarly, Scott (1994) conducted a study to investigate the effectiveness of intensive teaching programs on the students' academic performance in a set of courses in British literature and marketing. The results of his study showed a significant improvement in the students' academic abilities which, as he noted, can be due to the fact that the intensive program could promote a continuous learning process that improved student-teacher rapport more efficiently, and increased the students' motivation and commitment during the courses. Moreover, the effectiveness of intensive teaching/learning programs was also supported by the findings of Messina (1996) and Waechter's (1967) studies. The results of these two studies did not prove the superiority of the intensive program over the regular courses, but indicated that the students could have the same learning achievements in a shorter period of time. In addition, Nagano's (1995) examined the effect of a one-week English intensive course on a group of learners' achievements and attitudes towards learning English, and found its effect significantly positive.

However, the findings of this study proved Brown's (1992) claim wrong that intensive programs are only optimal for upper level students. In other words, the significant difference between the pre- and post-test results of the beginning level participants of the present study are in sharp contrast to Brown's (1992) theoretical view that intensive courses cannot be beneficial for elementary learners since they are not familiar with basic rules and therefore need slower pace of instruction. More precisely, these results revealed that the intensive program was beneficial for both elementary and intermediate level students.

As it has been mentioned so far, the results of this study are not consistent with the opponents of intensive teaching formats (Bateson, 1990; Henbery, 1997) who believe that intensive programs are inefficient. Bateson (1990), who is one of those opponents, compared intensive courses with traditional regular programs and found the regular courses more beneficial. Henbery's (1997) theoretical view is also inconsistent with the findings of the present study. He questions the success of intensive teaching programs in helping students to learn new materials. He claims that the pace of teaching in this kind of programs hampers the process of learning since the students are not given enough time to review the old materials before moving to the new ones. The performance 
of the learners in this study suggested that it was possible to achieve real gains in intensive programs.

\section{Conclusion}

The findings of the present study indicate promising outcomes for the CIEP and similar intensive English programs. As the results clearly indicated, all 30 students completed their assigned levels and passed. This would mean they all moved one level up from their previous competencies. Additionally, 17 students moved out of their 'elementary' level by passing level 103 - this would mean that they are ready for challenges at Intermediate Level. This is a great achievement. The intensive program at ELS Language Centers is a high-intensity program which involves 120 hours of study time per month. This is equivalent to more than half the total number of hours of English they would be exposed to in an entire school year! As attendance requirements are very stringent, students were required not to miss class for more than 3 days.

The 30 students were in touch with other students from various parts of the world who were working on their English so as to meet entry requirement at universities. This exposure would have lasting impressions on them and their motivation to learn English and work on their own preparations for tertiary education.

Another important feature of the present program was the field trips that the learners took to different historical and academic locations (Melaka, UNITEN, and UPM). Visits to interesting sites would provide an escape from the intensive exposure of the students to the materials and help them avoid monotony and boredom. Furthermore, the additional workshops in UPM and the Readerthon would add variety and foster learner engagement in the program. Based on the findings of the present study, at least three main conclusions can be made:

1. While in Malaysian schools there are attempts to bring back the teaching of Mathematics and Science in English, the approach taken in this study is more in line with the present policy - strengthening the teaching and learning of English as an important second language.

2. This One-Month Intensive Program is proof that real gains are achievable in intensive programs that stretch to 120 hours.

3. Collaboration between organizations is important for the success of such programs. MARA has shown great vision by taking the challenge. Their officers coordinated proceedings from Headquarters while the School principal mobilized the teachers and staff to assist. UPM allowed for the 30 students to stay in a residential college. Undergraduates and Post-graduate students on the TESL program helped with organizing activities for the 30 students. ELS language Centers provided the scholarships (tuition fees paid for) which amounted to RM54000 (about \$18000.00). UNITEN provided motivation talks for the students and finally, JUST ENGLISH Sdn. Bhd. (Malay: Sendirian Berhad, for 'private limited') donated 300 Magazines for the Readerthon.

It should, however, be noted that the present study has at least two major limitations that should be acknowledged at this point. The study lacked a control group. In experimental studies, a control group can determine if the effects of the treatment has, in fact, resulted from the treatment rather than other possible factors. Another limitation of the present study was the similarity of the pre- and post-tests. Since the distance between the two tests was only one month, the students could have learned from the pre-test and this could have affected their scores in the post-test. Further study with a control group and a more sophisticated form of pre- and post-tests is, therefore, necessary before the findings of this study can be generalized. Future research that investigates the effect of similar programs on learners' language proficiency over time may also lead to interesting outcomes.

\section{References}

Austin, A. M., \& Gustafson, L. (2006). Impact of Course Length on Student Learning. Retrieved on July 25, 2012, from http://www.economics-finance.org/jefe/econ/Gustafsonpaper.pdf

Bateson, D. (1990). Science achievement in semester and all-year courses. Journal Research in Science Teaching, 27, 23-40. http://dx.doi.org/10.1002/tea.3660270306

Bedard, F., \& Thomas, L. (2010). Impact des politiques linguistiques du Québec sur le développement de l'enseignement de l'anglais, langue seconde. Unpublished Master's Thesis, Université de Sherbrooke, Sherbrooke, Canada.

Brackenbury, R. L. (1987). What is more elusive than the learning of philosophy? Educational Research, 93-96.

Brown, D. H. (1992). Teaching literature in the intensive weekend format. Paper presented at the meeting of the College English Association, Pittsburgh, PA. (ERIC Document Reproduction service No. ED 354 519)

Burton, S., \& Nesbit, P. (2002). An analysis of student and faculty attitude to intensive teaching. Paper presented at 
the celebrating teaching and Macquire, Macquire University.

Buzash, M. D. (1994). Success of two-week intensive in program in French for superior high school students on a university campus. Paper presented at the Annual Meeting of the Central State conference on the Teaching of Foreign Languages, Kansas City, MO. (ERIC Document Reproduction Service No. ED 403 740)

Caskey, S. R. (1994). Learning outcomes in intensive courses. Journal of Continuing Higher Education, 42, 23-27. http://dx.doi.org/10.1080/07377366.1994.10400901

Daniel, E. L. (2000). A review of time-shortened courses across disciplines. College Student Journal, 34, 298-308.

Gallow, M. A., \& Odu, M. (2009). Examining the relationship between class scheduling and student achievement in college algebra. Community College Review, 36(4), 299-325. http://dx.doi.org/10.1177/0091552108330902

Grant, B. (2001). Using block courses for teaching logistics. International Journal of Physical Distribution and Logistics management, 31(7/8), p. 574. http://dx.doi.org/10.1108/09600030110402987

Gaubatz, N. (2003). Course scheduling formats and their impact on student learning. Retrieved on July 25, 2012, from http://www.ntlf.com/html/lib/suppmat/1201 course.htm

Henbery, K. (1997). The impact of class schedule on student performance in a financial management course. Journal of Education for Business, 73(2), 114. http://dx.doi.org/10.1080/08832329709601627

Hong-Nam, K., \& Leavell, A. G. (2006). Language learning strategies of ESL students in an intensive English learning context. System, 34(3), 399-415. http://dx.doi.org/10.1016/j.system.2006.02.002

Jacobs, H., Zingraf, S., Wormuth, D., Hartfiel, V. F., \& Hughey, J. (1981). Testing ESL composition: A practical approach. MA: Newbury House Publishers.

Jacques-Bilodeau, M. (2010). Research project: A study of the long term effects of Intensive English programs on secondary school ESL students. Retrieved on July 27, 2012, from www.csbe.qc.ca/projetrd/doc_projet/marie_jac_bil_2010.pdf

Messina, R. C. (1996). Power package: An alternative to traditional course scheduling. ERIC Document Reproduction Service, No. ED 396787.

Nagano, T. (1995). Nohongo no onsei kyoiku-Supichi komyunikeishon [Japanese oral expression education: Speech communication]. Tokyo, Japan: Tamagawa University Press.

Nasiri, E., \& Shokrpour, N. (2012). Comparison of intensive and non-intensive English courses and their effects on the student's performance in an EFL university context. European Scientific Journal, 8(8), 127-137.

Scott, P. A. (1994). A comparative of students, learning experiences in intensive and semester-length and of the attributes of high-quality intensive and -semester course learning. Paper presented at the Meeting of the North American Association of Summer Sessions Portland.

Scott, P. A., \& Conrad, C. F. (1991). A critique of intensive courses and agenda for research. Madrison WI: Division of Summer Sessions and inter-college programs, university of Wisconsin. ERIC ND. ED 337097.

Spade, N., \& Lightbown, P. M. (1994). Intensive ESL programs in Queen Primary School. TESOL Canada Journal/ Revue TESOL du Canada, 7, 11-32.

Spurling, S. (2001). Compression of Semesters or Intensity of Study: What is it that increases student success? ERIC Document Reproduction Service, No. ED467474.

Van Scyoc, L. J., \& Gleason, J. (1993). Traditional or intensive course lengths? A comparison of outcomes in economics learning. Journal of Economics Education, 24, 15-22. http://dx.doi.org/10.2307/1183319

Waechter, R. F. (1967). A comparison of achievement and retention by college junior students in an earth science course after learning under massed and spaced conditions. Doctoral dissertation, Pennsylvania State University. Dissertation Abstracts International, 27, 11-A.

Wodkowski, R. J. (2003). Accelerated learning in colleges and universities. New Directions for Adult and Continuing Education, 97, 5-15. http://dx.doi.org/10.1002/ace.84 